\title{
Post Renal Transplant Surgical Complications; MRI Standard Applications and Diagnostic Outcomes
}

\author{
Tarek Fawzy Abd Ella, Waleed Abdelfattah Mousa \\ Department of Diagnostic Radiology, Menoufia University, Menoufia, Egypt \\ Email address: \\ tarekvip100@yahoo.com (T. F. A. Ella),waleedmousa75@gmail.com (W. A. Mousa) \\ To cite this article: \\ Tarek Fawzy Abd Ella, Waleed Abdelfattah Mousa. Post Renal Transplant Surgical Complications; MRI Standard Applications and \\ Diagnostic Outcomes. International Journal of Medical Imaging. Vol. 5, No. 2, 2017, pp. 26-33. doi: 10.11648/j.ijmi.20170502.14
}

Received: December 31, 2016; Accepted: January 25, 2017; Published: March 25, 2017

\begin{abstract}
Objective: Fast MR imaging sequences together with paramagnetic contrast agents, offer multiple advantages in the assessment of renal function. It provides cross sectional and vascular information without the risk of ionizing radiation, iodinated contrast or arterial catheterization. Post transplantation complications can be grouped as surgical or medical. Immediate surgical complications include renal artery thrombosis or stenosis, urinary leak or lymphocele. Renal allograft frequently require repeated imaging studies during the immediate post-operative period and various times thereafter, when renal function is compromised. Background: End stage renal disease is common and can result from a variety of diseases. Kidney transplantation from living-related donors offered the best prognosis. Imaging modalities that are currently used to evaluate transplanted kidneys are ultrasound (US), computed tomography (CT), scintigraphy, intravenous urography (IVU), contrast angiography, and magnetic resonance imaging (MRI). Methods: This study was conducted on 181 renal transplant recipients. Recipients were 139 males and 42 females. Their age ranged from 20 to 58 years (mean age 39 years). The patients underwent clinical assessment, Laboratory investigations, and different Radiological imaging procedures as: I- Gray scale and color Doppler ultrasonography. II- Magnetic Resonance Imaging. 3D Gd-enhanced MRA. MR Urography. Selective IA-DSA of the graft artery. III- Percutaneous catheter nephrostomy (PCN) and antegrade pyelography. IV- Radio-isotope diuretic renogram using 99m Tc-MAG3. Results: 30 renal transplants were examined by MRI in the 1 st 2 weeks after renal transplantation. At the end of 1st 2 weeks, MR examinations were carried out, as basal studies (including MRI, MRA and MRU) for 98 transplants. From this group, 64 transplants were subjected to other MR examinations. After the 1st 2 weeks, 53 transplants were subjected to MR examinations for the 1st time at variable post-transplant duration. Among the studied 181 renal transplants, MR examinations detected 3 cases with graft arteries thrombosis (1.6\%), 10 with graft arteries stenosis (5.5\%), 6 with segmental infarctions (3.3\%), 3 cases with graft intrarenal arteries pseudo-aneurysms $(1.6 \%)$ and 2 cases with arterio- venous fistulae (1.1\%) after graft biopsies. Conclusion: MRI is highly recommended to evaluate intra-/extra-renal graft vascular lesions, urinary obstructive syndrome, compressive collections (urinoma, lymphocele), inflammatory and tumoral lesions of the renal graft.
\end{abstract}

Keywords: Magnetic Resonance Imaging, Diuretic Renogram, Antegrade Pyelography, Renal Transplant, Surgical Complications

\section{Introduction}

End stage renal disease is common and can result from a variety of diseases. The expense and morbidity of dialysis has made renal transplantation the preferred treatment whenever available (1). Kidney transplantation from livingrelated donors offered the best prognosis, a superior quality of life (as compared with hemodialysis or peritoneal dialysis) and improved rehabilitation (2). Imaging modalities that are currently used to evaluate transplanted kidneys are ultrasound (US), computed tomography (CT), scintigraphy, intravenous urography (IVU), contrast angiography, and magnetic resonance imaging (MRI) (3).

Fast MR imaging sequences together with paramagnetic contrast agents, offer multiple advantages in the assessment of renal function. It provides cross sectional and vascular 
information without the risk of ionizing radiation, iodinated contrast or arterial catheterization (4). Post transplantation complications can be grouped as surgical or medical. Immediate surgical complications include renal artery thrombosis or stenosis, urinary leak or lymphocele. Medical complications include rejection, cyclosporine toxicity and acute tubular necrosis (ATN) (5). Renal allografts frequently require repeated imaging studies during the immediate postoperative period and various times thereafter, when renal function is compromised (6).

This study aims to evaluate: the capability of MRI applications to diagnose and differentiate various post transplantation surgical complications.

\section{Methods}

A- Gray scale and color Doppler ultrasonography:

- Routinely performed for all examined recipients before MR examinations.

- Equipment: Acuson sequoia 512 gray scale ultrasonography, with $5 \mathrm{MHZ}$ multi-frequency curved linear array transducer, was used to exclude obstruction and peri-graft collection. Cross section area of the graft was measured as an indicator for overall graft size. Color-coded duplex Doppler and color Doppler energy (power Doppler) were performed at each study to measure the intra-renal RI and to evaluate the cortical perfusion.

B-Magnetic Resonance Imaging:-

- 30 patients were examined immediately postoperative (within the $1^{\text {st }}$ two weeks) due to rapid deterioration of graft function i.e. rising serum creatinine, oliguria or development of hypertension.

- 98 patients were examined after 2 weeks (Basal MR examinations) among those, 64 patients were reexamined by MR imaging at variable times.

- 53 patients were examined long after renal transplantation with no previous basal MR examinations.

- The number of MR examinations per patient ranged from 1 to 2 with a total number of 245 examinations.

- All patients were examined as follow:-

1. No specific preparatory advice apart from nothing by mouth for 2 hours.

2. Equipment: - 1.5 tesla MR scanner.

3. Technique: - the following pulse sequences were performed for all examined renal allograft.

a-Coronal and sagittal localizers. b-Sagittal and axial SE $\mathrm{T}_{1}$ weighted images.

c-Axial and coronal FSE $\mathrm{T}_{2}$ weighted images. d-Axial and coronal post-contrast gradient images.

- 3D Gd-enhanced MRA:-

- Large field of view to encompass the lower abdominal aorta, iliac arteries and graft artery extending down to the femoral head.

- Coronal and sagittal localizers:-

- Contrast enhanced MRA:-
- Multiphase imaging option i.e. arterial and venous phases. Each phase lasts $12 \mathrm{sec}$. with patient holding his breath and 10 sec. interval between two phases.

- Phase contrast (PC) MRA was performed in conjunction with TOF-MRA in 30 cases with tortuous main graft artery or suspected graft artery stenosis.

- Post-processing techniques for evaluation of $\mathrm{Gd}$ enhanced MRA:-

- 3D reconstruction with MIP images:

It was routinely done for all examined (181) recipients and carried out on a second console (ultra. Spark /1/sun micro system).

- MPR images:

MPR images were performed for 71 cases in which multiple graft arteries were surgically reported, tortuous main graft artery and vascular complications were suspected from routine MIP images.

- Axial and coronal post-contrast gradient images:

- Routinely performed for all examined patients immediately after MRA and just before excretory MRU.

- Imaging analysis:

1) Presence of non-enhancing parenchymal (nephrographic) defects.

2) Assessment of enhancement pattern of renal (parenchymal) and/or peri-renal masses as well as cystic fluid collections.

- MRU:-

For assessment of the graft size, pelvi-calyceal system configuration and ureter.

(a) Gd-enhanced excretory MRU:

Routinely performed after MRA for all examined renal allografts.

- Coronal oblique contrast enhanced MRU:

- 3D reconstruction with MIP is used to evaluate of the following:

- Renal allograft parenchyma for; shape, size, contour of the kidney and presence of parenchymal filling defects.

- Pelvi-calyceal system for its shape (e.g. compression, displacement and stretching), and presence of any filling defects (e.g. Blood clots and stones).

- Ureter and uretero-vesical anastomosis for detection of course and caliber of the ureter and presence of any filling defects.

- Urinary leaks and fistulae.

(b) T2-weighted static MRU:

-Heavy T2-weighted MRU:

Performed for 98 cases with rising serum creatinine above $2 \mathrm{mg} / \mathrm{dl}$, dilated pelvi-calyceal system with or without dilated ureter, presence of perigraft collection (on routine US examination) and in suspected cases of urinary leaks.

- Single-shot MRU:

Performed for 98 recipients (in whom static T2-weighted MRU was performed).

$C$-Other imaging modalities whenever needed:-

1) Radio-isotope diuretic renogram using ${ }^{99 m} \mathrm{Tc}_{\mathrm{C}} \mathrm{MAG_{3 }}$ :-

- Performed for 90 cases (rising serum creatinine immediately after transplantation and suspected graft 
obstruction).

2) Percutaneous catheter nephrostomy (PCN) and antegrade pyelography:

- Performed for 15 cases (in presence of urinary leakage, renal stones and rising serum creatinine secondary to graft obstruction).

3) Selective IA-DSA of the graft artery:

- Performed for 8 patients as a preliminary step of angioplasty.

Classification of post renal transplant surgical complications (7):-

1. Vascular complications:-

A-Renal vein thrombosis.

B-Renal artery stenosis.

C-Graft infarction.

D-Graft arterio-venous fistulae and pseudo-aneurysms.

2. Urologic complications:-

A-Urinary leak.

B-Ureteral Necrosis.

C-Ureteral obstruction.

D-Vesico - ureteric reflux.

E- Renal transplant torsion.

F- Renal transplant Rupture.

G-Calculi.

3. Peritransplant Fluid Collections:-

A-Haematoma.

B-Urinoma.

C-Lymphocele.

D-Abscess.

\section{Results}

This study was carried out on 181 renal transplant recipients, their age distribution ranged from 20 to 58 years (mean age 39 years). They were 139 males and 42 females.

Among the studied 181 renal transplants, MR examinations detected 3 cases with graft arteries thrombosis (1.6\%), 10 with graft arteries stenosis (5.5\%), 6 with segmental infarctions $(3.3 \%), 3$ cases with graft intrarenal arteries pseudo-aneurysms (1.6\%) and 2 cases with arterio- venous fistulae (1.1\%) after graft biopsies.

Table 1. Post-transplant vascular complications detected by MRA and $G d$ enhanced MRI among the 181 cases.

\begin{tabular}{lll}
\hline Vascular complications & No. of patients & $\mathbf{\%}$ \\
\hline Graft artery thrombosis & 3 & $1.6 \%$ \\
Graft artery stenosis & 10 & $5.5 \%$ \\
Segmental infarction & 6 & $3.3 \%$ \\
Graft artery pseudo-aneurysm & 3 & $1.6 \%$ \\
Graft arterio- venous fistula & 2 & $1.1 \%$ \\
Total & 24 & $13.1 \%$ \\
\hline
\end{tabular}

No surgical interference or interventional procedures were performed for patients with segmental infarctions, those with graft arteries pseudo-aneurysms and arterio-venous fistulae, as the infracted areas were small and the follow up colorDoppler US of the grafts showed spontaneous thrombosis of the pseudo-aneurysms and obliteration of the fistulae with no need for embolization.

In our study, the 3 cases with graft arteries thrombosis as diagnosed by Gd-enhanced 3D MRA were surgically explored where 2 cases were managed by graft nephrectomy and the $3^{\text {rd }}$ case with incomplete arterial thrombosis was managed by thrombus removal and graft survival. Among the diagnosed cases with graft arteries stenosis (10 cases), surgical re-anastomosis of the graft arteries to the internal iliac arteries were performed in 2 patients with arterial atherosclerosis and calcified arterial wall in one patient and failure of previous angioplasty in the other one. IA-DSA for the remaining 8 patients were performed as a preliminary step for angioplasty and revealed 6 cases with significant arterial stenosis who were subjected to balloon dilatation while the remaining 2 cases showed no evidence of stenosis.

The MRA findings for graft arteries thrombosis, as compared with surgical findings, were $100 \%$ as regarding sensitivity, specificity and overall accuracy while those for graft arteries stenosis as compared to the IA-DSA and surgical findings were $100 \%, 98.8 \%, 98.9 \%$ and $80 \%$ as regarding sensitivity, specificity, overall accuracy and positive predictive value.

Table 2. Showed correlation between operative findings, IA-DSA and MRA findings in evaluation of post renal transplant vascular complications.

\begin{tabular}{llllllllll}
\hline & \multicolumn{1}{l}{ Operative findings } & IA-DSA & \multicolumn{2}{l}{ MRA findings } \\
\cline { 2 - 10 } & $\begin{array}{l}\text { No. of } \\
\text { Patients }\end{array}$ & findings & $\begin{array}{l}\text { No. of } \\
\text { Patients }\end{array}$ & findings & $\begin{array}{l}\text { No. of } \\
\text { Patients }\end{array}$ & sensitivity & Specificity & $\begin{array}{l}\text { Overall } \\
\text { accuracy \% }\end{array}$ & $\begin{array}{l}\text { Positive predicative } \\
\text { value \% }\end{array}$ \\
\hline G. A thrombosis & 3 & 3 & - & - & 3 & $100 \%$ & $100 \%$ & $100 \%$ \\
\\
G. A stenosis
\end{tabular}

The sensitivity, specificity, overall accuracy and positive predictive values for detection of graft arteries stenosis were calculated and were $100 \% 90.9 \%, 93.3 \%, 80 \%$, for $3 \mathrm{D}$ FSPGR and $100 \%, 95.4 \%, 96.7 \%$ and $88.9 \%$ for $3 \mathrm{D}-\mathrm{PC}$ respectively.

The sensitivity, specificity and overall accuracy of MIP images and MPR images, as post-processing techniques, performed for 71 patients in evaluation of surgically and interventionally suspected vascular complications were;
$66.6 \%, 100 \%, 98.6 \%, 100 \%, 96.8 \%$ and $97.2 \%$ for Graft arteries thrombosis and graft arteries stenosis detected by MIP images while they were $100 \%$ for MPR in detection of graft artery thrombosis and $100 \%, 98.4 \%$ and $98.6 \%$ in detection of graft arteries stenosis.

As regarding the post-transplant urological complications Gd-enhanced dynamic MRU detected 4 out of 6 cases with urinary leakage (66.6\%), 2 cases with PUJO (100\%), 4 cases with ureteral obstruction (80\%). Gd-enhanced MRU detected 
1 case with renal pelvis and lower calyceal stone (50\%) while the other 1 case was interpretated as normal.

MR examinations detected 6 cases with peri-graft haematomas $(85.7 \%)$ while the remaining 1 case was interpretated as lymphocele. 5 cases of 6 with urinomas were detected $(83.3 \%)$ while the remaining 1 case was diagnosed as lymphocele, 8 cases of 10 with perigraft lymphoceles were diagnosed $(80 \%)$ while the remaining 2 cases were interpretated as peri-graft haematomas. MR detected the 3 cases with abscesses formation (100\%), 2 were intrarenal while the $3^{\text {rd }}$ was perirenal in location.

Compared with interventional findings, the sensitivity, specificity, overall accuracy, positive and negative predicative values for MR findings were calculated as follows; for haematomas $85.7 \%, 98.9 \%, 99.4 \%, 75 \%$ and $99.4 \%$, for urinomas $83.3 \%, 100 \% 99.4 \% 100 \%$ and $99.4 \%$ and for detection of lymphoceles $80 \%, 98.8 \%, 98.9 \%, 80 \%$ and $98.8 \%$.

Table 3. Showed the distribution of post-transplant surgical complications among the study groups according to MR findings and dates of examinations.

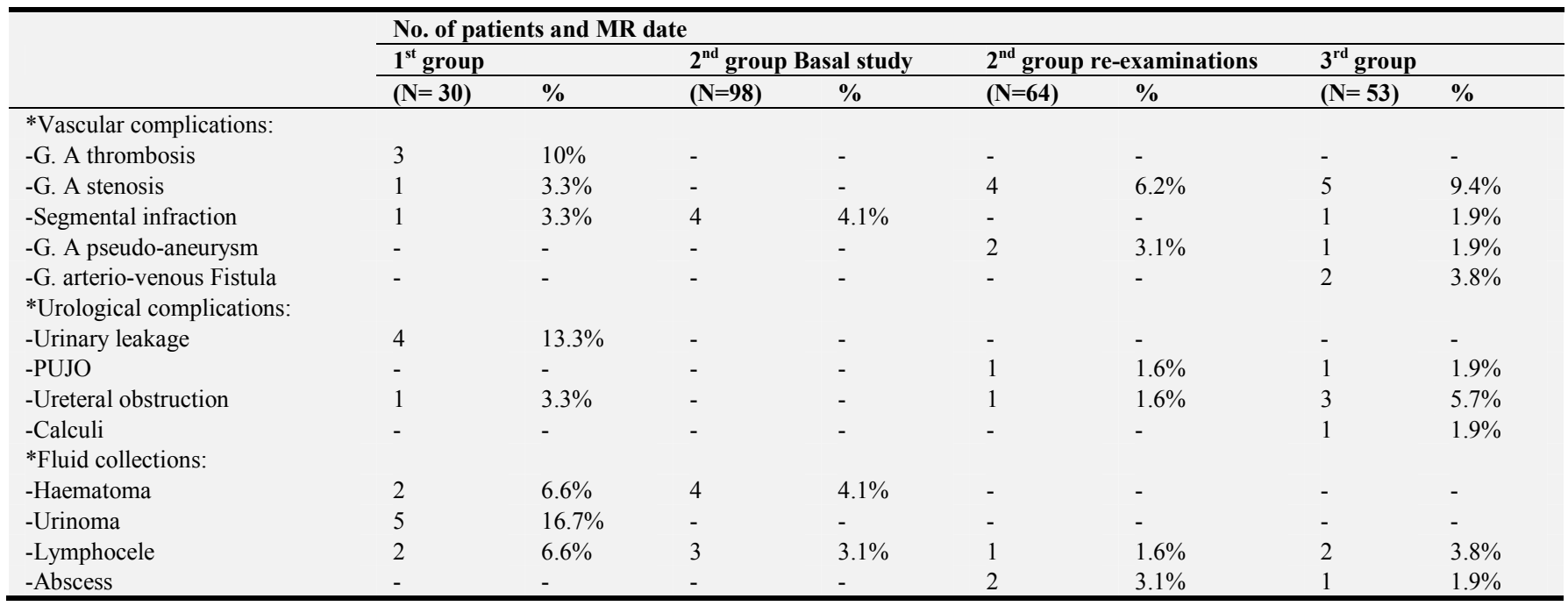

\section{Discussion}

The incidence of vascular complications in our study group was comparable to those reported by Liu X et al. (8); graft artery thrombosis $(1 \%)$, graft artery stenosis $(1.5 \%-$ $10 \%)$ and graft artery pseudo-aneurysm (1\%).

We had $100 \%$ sensitivity, specificity, overall accuracy and positive predictive value for MRA in detection of graft artery thrombosis and $100 \%, 98.8 \%, 98.9 \%$ and $80 \%$ for graft artery stenosis respectively. MRA detected 3 cases with graft artery thrombosis $(1.6 \%)$, 10 with graft artery stenosis $(5.5 \%)$, 6 with segmental infarction $(3.3 \%)$ and 3 cases with post biopsy graft pseudo-aneurysms $(1.6 \%)$. The sensitivity and specificity of detecting graft artery stenosis in our study were comparable to those reported by Aneesh Srivastava et al. (9) and were $100 \%$ and $98 \%$ respectively.

The sensitivity, specificity, overall accuracy and positive predictive values for 3D- Gd enhanced FSPGR MRA and 3D- PC MRA, performed for 30 patients, for the detection of graft arteries stenosis were:

Table 4. Sensitivity, specificity, accuracy and positive predictive values for MRA.

\begin{tabular}{lll}
\hline & 3D-Gd enhanced FSPGR & 3D-PC MRA \\
& MRA & \\
\hline Sensitivity & $100 \%$ & $100 \%$ \\
Specificity & $90.9 \%$ & $95.4 \%$ \\
Overall accuracy & $93.3 \%$ & $96.7 \%$ \\
Positive predictive value & $80 \%$ & $88.9 \%$ \\
\hline
\end{tabular}

These data are comparable to those reported by Liu X et al. (8) concerning the sensitivity and specificity for 3D- TOF and 3D- PC MRA in evaluation of post renal transplant artery stenosis which were:

Table 5. Liu X. et al, sensitivity and specificity for MRA.

\begin{tabular}{lll}
\hline & 3D TOF MRA & 3D-PC MRA \\
\hline Sensitivity & $90 \%$ & $94 \%$ \\
Specificity & $88 \%$ & $85 \%$ \\
\hline
\end{tabular}

However our data are incomparable to those reported by Huber et al. (10) which were:

Table 6. Huber sensitivity and specificity for MRA.

\begin{tabular}{lll}
\hline & 3D TOF MRA & 3D-PC MRA \\
\hline Sensitivity & $47 \%$ & $60 \%$ \\
Specificity & $81 \%$ & $76 \%$ \\
\hline
\end{tabular}

The sensitivity, specificity an overall accuracy of MIP and MPR images were $66.6 \%, 100 \%, 98.6 \%$ and $100 \%$ for detection of graft arteries thrombosis while they were $100 \%$, $96.8 \%, 97.2 \%, 100 \%, 98.4 \%$ and $98.6 \%$ for detection of graft arteries stenosis.

These results are comparable to those of Hany et al. (11) which were $96 \%, 91 \%$ and $92 \%$ for MIP, regarding sensitivity, specificity and overall accuracy in detection of renal artery stenosis while for MPR they were $96 \%, 97 \%$ and $96 \%$. In spite of the short post-processing times for MIP images, they are handicapped by projection -related 
limitations in a manner identical to conventional catheter angiogram. Eccentrically located stenosis and superimposition of structures may simulate the presence of stenosis; therefore MIP images are generally acquired in two or more projections.

The sensitivity, specificity and overall accuracy for Gdenhanced MRU in detection of urinary leakage were $66.6 \%$, $100 \%$ and $97.9 \%$ while both heavy $\mathrm{T}_{2} \mathrm{~W}$ and single-shot MRU failed to detect any urine leak. Our results, concerning the superiority of Gd- enhanced MRU in detection of posttransplant urinary leakage agree with Claus et al. (12) who reported that Gd- enhanced MRU is a very accurate and promising imaging technique for the detection of urinary leaks and fistula.

The misdiagnosed one patient with ureteral obstruction was due to marked hydrouretronephrosis with subsequent delayed excretion of Gd- DTPA and inaccurate localization of the obstruction level in both source images and MIP image The sensitivity, specificity and overall accuracy for Gdenhanced MRU in detection of ureteral obstruction were $80 \%$, $100 \%$ and $98.9 \%$ and for both heavy $\mathrm{T}_{2} \mathrm{~W}$ and single- shot MRU they were $100 \%$. These results concerning static heavy $\mathrm{T}_{2} \mathrm{~W}$ MRU were comparable to those reported by Schubert et al. (13) and were $80 \%, 100 \%$ and $98.8 \%$.

As regarding the peri-transplant fluid collections; hematoma is common in the immediate postoperative period. It is usually small and resolves spontaneously while large haematoma may displace the transplanted kidney producing hydronephrosis or rupture intraperitoneally and may produce shock. In such cases diagnostic aspiration with or without percutaneous drainage may be performed (2).

Urinoma is usually found between the transplanted kidney and the bladder in the first one or two weeks post-operatively. It occurs because of continued, slow extravasation of urine from the renal pelvis, ureter or uretero-vesical anastomosis (14). Lymphocele occurs either in early postoperative period or in late postoperative period. If large, it increases progressively in size causing hydronephrosis and requires drainage (15). Abscess formation can arise de novo, or it may be due to superimposition of a peri-transplant fluid collection. Needle aspiration with either surgical or sonographically guided percutaneous drainage is performed (14).

In our study; MRI detected six of seven patients with perigraft hematomas $(85.7 \%), 5$ of 6 patients with urinomas $(83.3 \%), 8$ of 10 patients with lymphoceles $(80 \%)$ and 3 cases with abscesses formation (100\%). The remaining one patient with peri-graft hematoma was interpreted as lymphocele; this was due to central liquefaction of the haematoma and higher SI than that of urine (U.B).

The misdiagnosed one patient with urinoma was diagnosed as lymphocele; this may be attributed to the presence of small associated peri-graft hematoma altering the signal intensity in both T1 and T2- W MR images. While the remaining misdiagnosed two patients with lymphoceles were interpretated as perigraft hematomas due to presence of small associated perirenal hematoma and masking of peri-renal fat which gave high signals in both $\mathrm{T}_{1}$ and $\mathrm{T}_{2}$ WIs.

Our results, concerning the distribution of posttransplantation fluid collections, are comparable to Fang et al. (8) in that the patients with peri-graft hematomas and urinomas were detected within the $1^{\text {st }}$ postoperative two weeks while those with lymphoceles and abscesses formation were detected at variable post-operative periods.

\section{Conclusions}

The study demonstrated that Gd-enhanced MRA (utilizing both FSPGR and PC) of the transplant artery with MPR alone /or with MIP images as post-processing techniques assessed graft artery stenosis with high accuracy, complementary Gdenhanced FSPGR $\mathrm{T}_{1}$ weighted MR images and Gd-enhanced MRU allowed rapid Global assessment of the renal parenchyma, pelvi-calyceal system and ureter together with the peri-transplant region for enhancing masses or fluid collections. MRA can replace IA-DSA in patients with impaired renal function while conventional IA-DSA of the graft artery is reserved for those with positive MR angiographic findings as a preliminary step for interventional technique (percutaneous balloon dilatation).

MRU is a valuable non invasive, non nephrotoxic technique for the assessment of renal transplants in cases with suspicion of complication in the excretory system. Gdenhanced MRU is a promising alternative in evaluation of post-transplant urinary leakage, non dilated urinary tract with no hazards of radiation exposure or iodinated CM. static $\mathrm{T}_{2^{-}}$ weighted MRU is restricted to cases with dilated pelvicalyceal system and impaired excretory function of the graft.

The addition of diffusion MRI is helpful in many situations of post-transplant complications.

Case No. (1)

A 40 year old male patient transplanted since 3 days presented with accidentally discovered hypo-echoic fluid collection and mild hydronephrosis on routine post-operative US.

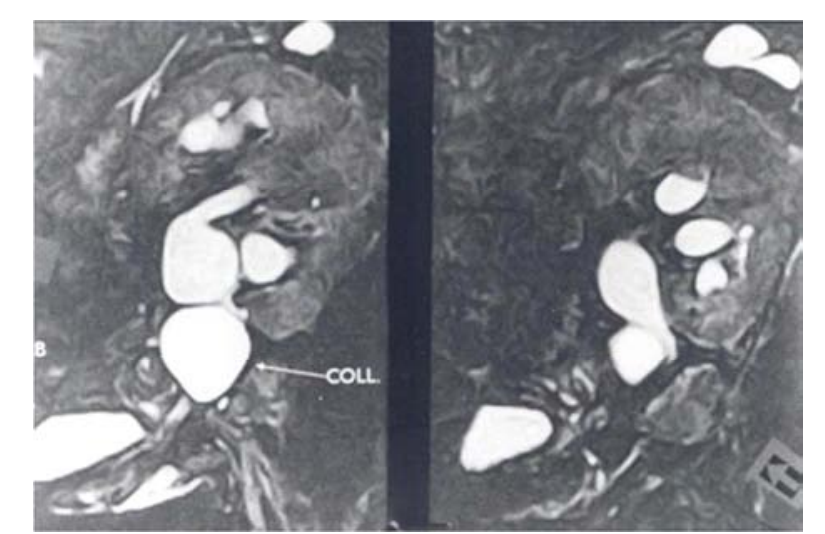

Figure 1. Static heavy T2W MRU shows; peri-graft collection compressing the upper part of the ureter with subsequent proximal hydroureteronephrosis. 


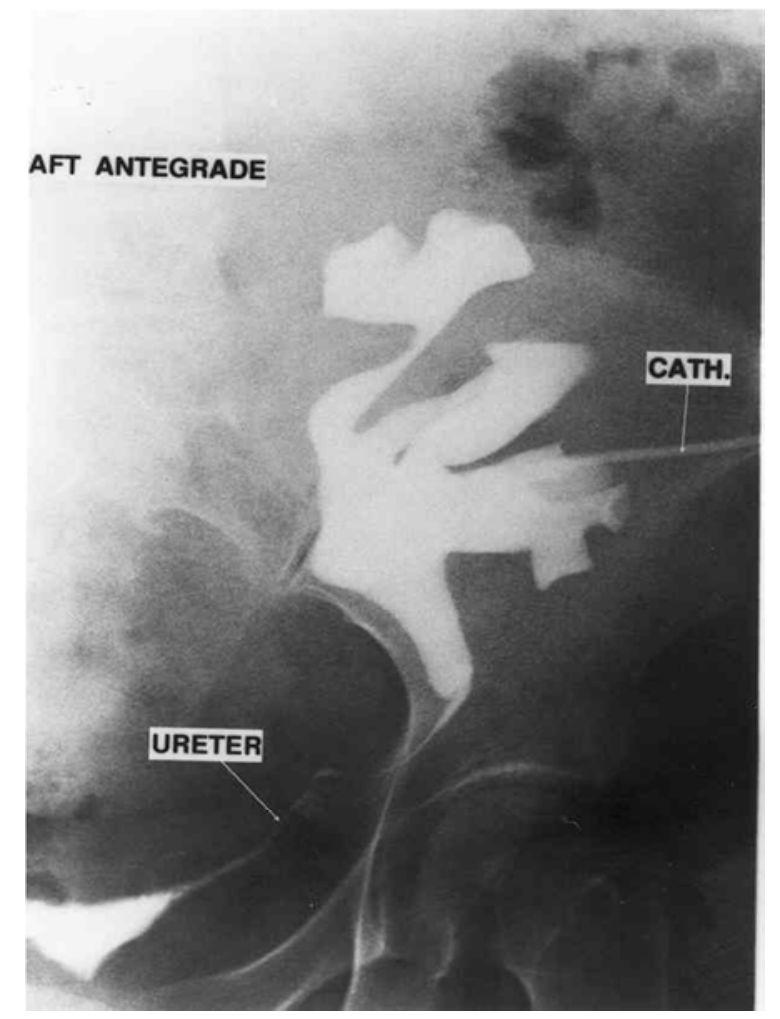

Figure 2. Graft PCN and antegrade pyelography show hydroureteronephrosis with lateral deviation of the upper part of the ureter.

Case No. (2)

A 25 year old male patient transplanted since 2 days presented with accidentally discovered pelvic free fluid on routine post-operative US.

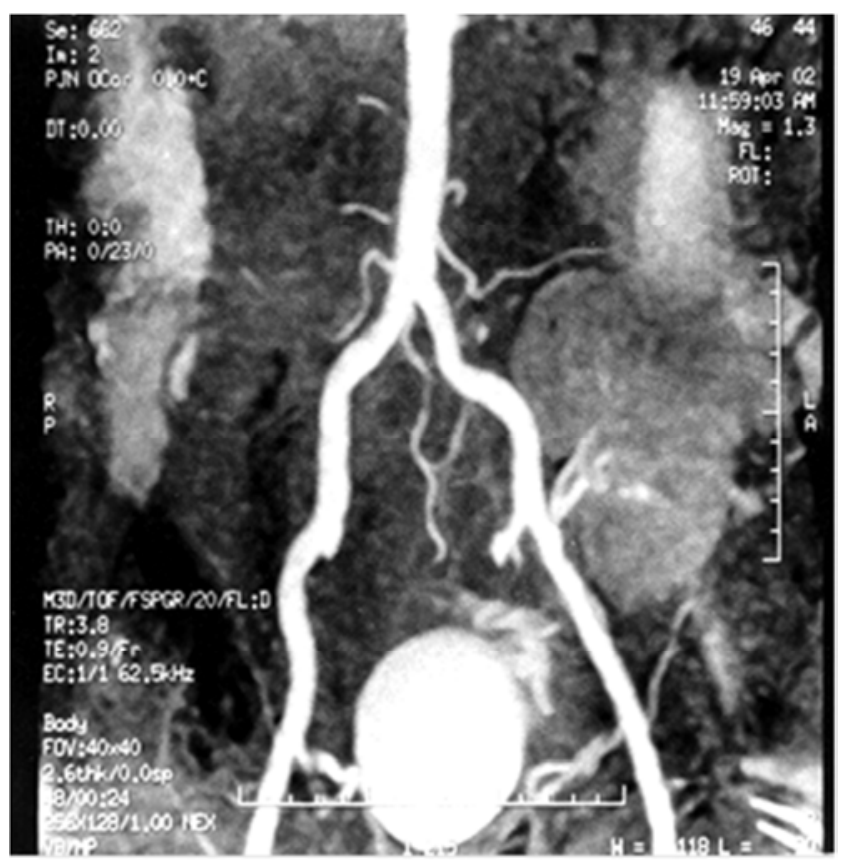

Figure 3. Gd-enhanced 3D- FSPGR MRA with MIP image shows; single graft artery (arrow), early opacification of urinary bladder and the site of urinary leakage (bent arrow).

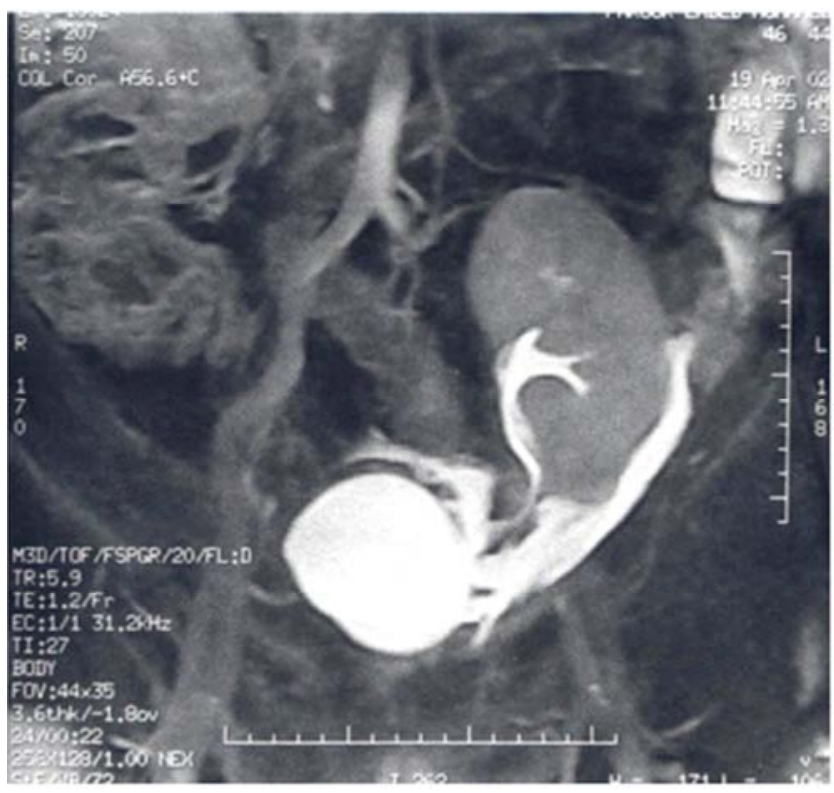

Figure 4. Gd-enhanced excretory MRU with MIP image shows normal appearance of the pelvi-calyceal system; Normal caliber of the ureter and contrast enhanced urinary leakage (arrows).

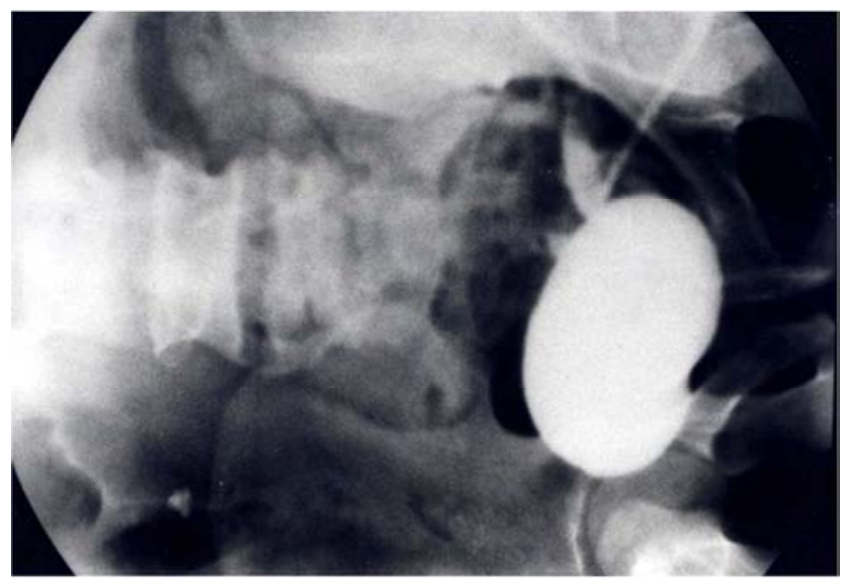

Figure 5. Ascending cystogram shows the urinary leakage from the site of uretero-vesical anastomosis (arrow).
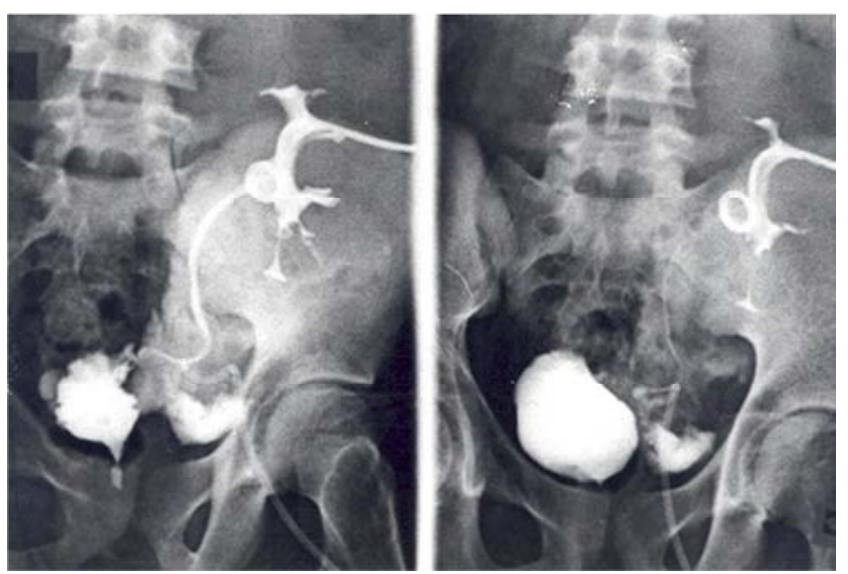

Figure 6. Graft PCN and antegrade pyelography show normal configuration of pelvi-calyceal system and ureter with urinary leakage to the left side of urinary bladder (arrows). 
Case No. (3)

A 36 year old male patient transplanted since 3 days presented with abnormal arterio-venous color flow signals on routine Doppler US after graft biopsy.

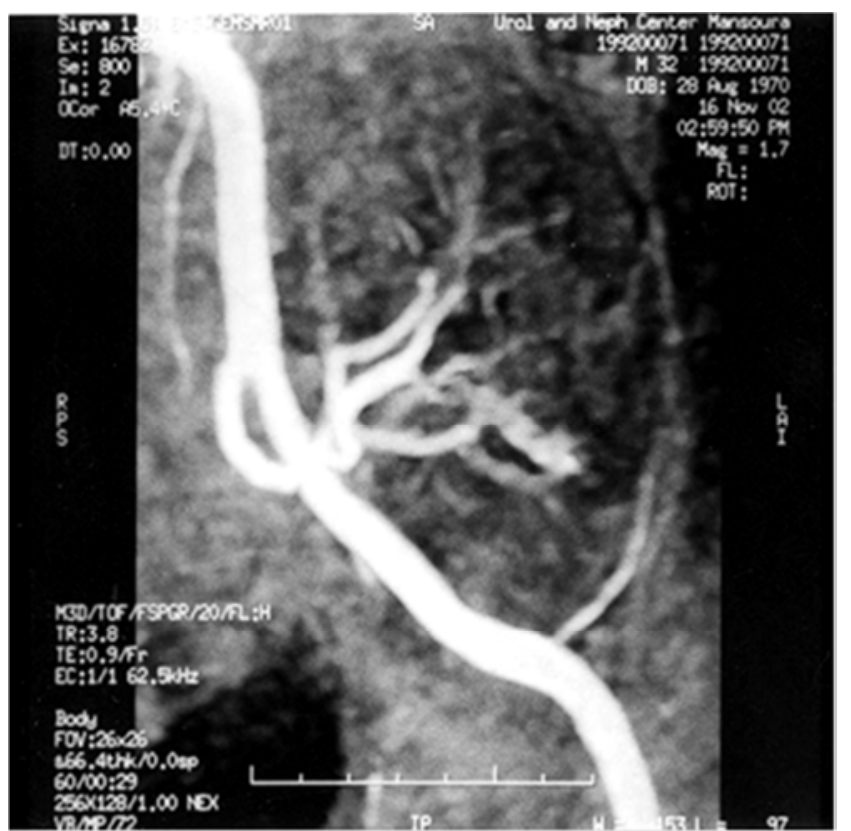

Figure 7. Gd-enhanced 3D- FSPGR MRA with MIP image shows venous filling during the early arterial phase (arrows) secondary to abnormal arterio-venous communication (A-V fistula).

\section{References}

[1] Onniboni M, R, Coco L, Zompatori M, Sverzellati N, Rossi C.: Magnetic resonance imaging in the complications of kidney transplantation. Radiol Med. Oct 22, 2012.

[2] Barry JM, Conlin MJ. Renal transplantation. In: Wein AJ, editor. Campbell-Walsh Urology. 10th ed. Philadelphia, Pa: Saunders Elsevier; p. 1279_1289. 2011.

[3] Lamb KE, Lodhi S, Meier-Kriesche HU: Long-term renal allograft survival in the United States: A critical reappraisal. Am. J. Transplant.; 11: 450-462. 2011.

[4] Hohenwalter M. D, Skowlund C. J., Erickson S. J, Hariharan S, Rilling W. S., Crain M. R., and Drescher P :.Renal transplant evaluation with MR angiography and MR imaging. Radiographics, 21, (6), 1505-1517, 2001.

[5] Choyke ,P. L., Becker, J. A., and Zeissman ,H. A :.Imaging the transplanted kidney in: Pollack, H. M., and Mcclennan, B. L., eds :(Clinical urography 2nd edition .Vol (3), Ch, (106), W. B Saunders, Philadelphia: 3091-3118, 2000.

[6] Akbar SA, Jafri SZ, Amendola MA, Madrazo BL, Salem R, Bis KG.: Complications of renal transplantation. Radiographics 25: 1335-1356, 2005.

[7] Safa J, Nezami N, Tarzamni M. K., Zarforooshan S, RahimiArdabili B and Bohlouli A.: Post-transplant urological and vascular complications. Saudi Journal of Kidney Disease Transplantation, 20 (5): 867-71, 2009.

[8] Liu X, Berg N, Sheehan J, et al. Renal Transplant:
Nonenhanced Renal MR Angiography with Magnetizationprepared Steady-State Free Precession 1. Radiology; 251: 535-542. 2009.

[9] Aneesh Srivastava, Jatinder Kumar, Sandeep Sharma, Abhishek, MS Ansari, and Rakesh Kapoor. Vascular complication in live related renal transplant: An experience of 1945 cases. Indian J Urol. Jan-Mar; 29 (1): 42-47. 2013.

[10] Huber H., Heuck A., Scheidler J., Holzknecht N., Baur A., Stangl M., Theodorakis J., D-Illner W., Land W. and Reiser M.: Contrast-enhanced MR Aniography in patients after kidney transplantation. Eur. Radiol. 11:2488-2495, 2001.

[11] Hany T. F., Schmidt M., Davis C. P .Göhde S. C. and Debatin J. F.: Diagnostic impact of four post-processing techniques in evaluating contrast enhanced 3D-MRA. AJR. 170: 907912.1998.

[12] Claus C. A., Adam G. B. and Günther R. W :.MR urography: examination techniques and clinical applications. Eur .Radiol, 11: 355-372, 2001.

[13] Schubert R. A., Gockeritz S., Mentzel H. J., Rzanny R., Schubert J. and Kaiser W. A.: Imaging in ureteral complications of renal transplantation: value of static fluid MR urography. Eur. Radiol. 10 (7): 1152-1157, 2000.

[14] Lupescu IG, Capsa RA, Popa GA, Medar C, Nicolae AC, Preda EM, Flintoaca A, Lesaru M, Sinescu I. CT and MRI diagnostic value of renal posttransplant complicationsexperience of Fundeni Clinical Institute. XIXth Romanian Congress of Radiology and Medical Imaging, Bucharest, 1113 October, 2013.

[15] Nixon JN, Biyyam DR, Stanescu L, Phillips GS, Finn LS, Parisi MT. Imaging of Pediatric Renal Transplants and Their Complications: A Pictorial Review. RadioGraphics, 33: 12271251, 2013.

[16] Fang Y. C., and Siegelman E. S.: Complications of Renal transplantation: MR findings. Journal of computer Assistant Tomography. 25 (6): 836-842, 2001.

[17] Boeve W. J, Kok T, Tegzess, A. M., Van son, W. J, Ploeg R. J, .Sluiter W. J., and Kamman R. L :Comparison of contrast enhanced MR angiography- MRI and digital subtraction angiography in the evaluation of pancreas and/or kidney transplantation patients: Initial experience. Magn .Reson. Imaging. 19 (5): 595-607. 2001.

[18] Irtan S, Maisin A, Baudouin V, Nivoche Y, Azoulay R, Jacqz E, and Aigrain Y.: Renal transplantation in children: Critical analysis of age related surgical complications. Pediatric Transplant. Jan 11, 2010.

[19] Luk S. H., Chan J. H .wan T. H, Tsui W. C., Cheung Y. K. and Yuen M. K :.Breath-hold 3D-Gd-enhanced subtraction MRA in the detection of transplant renal artery stenosis .Clin . Radiol. 54 (10): 651-654, 1999.

[20] Dunnick N. R., Sandler C. M. and Newhouse J. H :.Renal transplantation in: Text book of uroradiology .Ch. (12): 242 . Lippincot Williams and Wilkins. 2001.

[21] Sato N., Kobayashi H., Hiraga A., Saga T., Togashi K., Konishi J., and Brechbiel M. W :.Pharmacokinetics and enhancement patterns of macromolecular MR contrast agents with various sizes of polyamidoamine dendrimer cores .Magn. Reson .Med. 46 (6): 1169-1173. 2001. 
[22] Heverhagen J. T., Funck R. C., Schwarz U., .Zoefel P., Matschl V., Klose K. J. and Wagner H. J :Kinetic evaluation of an I. V bolus of MR contrast media .Magn .Reson .Imaging 19 (7): 1025-1030. 2001.

[23] EL-Diasty T, Ateia M, and Kamal T; Comprehensive MR Evaluation of potential kidney transplant donors. European society of urogenital Radiology meeting (ESUR 2000). Eur . Radiol. 10, abstracts): E1 - E26. 2000.

[24] Hany T. F., Schmidt M., Da Fervenza F. C., Lafayette R. A, Alfery E. J. and Petersen $\mathrm{J}$ :.Renal artery stenosis in kidney transplantation. Am. J .kidney .Dis. 31: 142-148. $1998 .$.

[25] Namimito T., Yamashita, Y .Mitsuzaki K., Nakayama Y., Tango Y. and Takahashi $\mathrm{M}$ :.Measurement of the apparent diffusion coefficient in diffuse renal diseases by diffusion weighted echo-planar imaging. J. MRI. 9: 832-837, 1999.

[26] Bracale UM, Carbone F, del Guercio L, Viola D, D Armiento FP, Maurea S, et al. External iliac artery pseudoaneurysm complicating renal transplantation. Interact Cardiovasc Thorac Surg.; 8: 654-60, 2009.

[27] Poels JA, Riley PL. Extrarenal transplant artery pseudoaneurysm: A combined therapeutic approach. Cardiovasc Intervent Radiol.; 31: 404, 2008.

[28] Womer KL, Kaplan B: Recent developments in kidney transplantation; A critical assessment. Am J Transplant; 9: 1265-1271, 2009.

[29] Schenk, J. P, Hansmann J, Hallscheidt P, Weingard K., Wiesel, M., Leutloff C. U., Dux, M., Richter, G. M., and Kauffmann, G. W: Radiodiagnosis following kidney transplantation. Radiology, 39; 404-414, 1999.
[30] Ngai S, Demetriades T: Prediction of long-term renal transplant allograft function from day 3 post-transplant Tc99m MAG3 scintigraphy. Clin Nucl Med; 33: 102-105, 2008.

[31] Guignard R, Mourad G, Mariano-Goulart D: Utility of postsurgical renal scintigraphy to predict one-year outcome of renal transplants in patients with delayed graft function. Nucl Med Commun; 32: 314-319, 2011.

[32] Gupta SK, Lewis G, Rogers K, et al: Quantitative Tc-99m DTPA renal transplant scintigraphy predicts graft survival in the very early post- operative period. Nucl Med Commun; 33: 1292-1299, 2012.

[33] Grenier N, Merville P and Pasticier G. Renal Transplantation: Epidemiological, Clinical, Radiological and Surgical Considerations, in Imaging in Transplantation, Springer, 5598, 2008.

[34] Thoeny HC, De Keyzer F. Diffusion-weighted MR Imaging of Native and Transplanted Kidneys. Radiology, 259: 25-38, 2011.

[35] Prabhakar Rajiah, Yit Yoo Lim, Paul Taylor: Renal transplant imaging \& complications, Abdom. Imaging (2006) 31: 735746, published online 21 February 2007.

[36] Martin DR, Sharma P, Salman K, Jones RA, Grattan-Smith JD, Mao H, Lauenstein TC, Burrow BK, Dana LRT.: Tudorascu and Votaw JR: Individual Kidney Blood Flow Measured with Contrast enhanced First-Pass Perfusion MR Imaging. Radiology: 246: 1; 241: 248, 2008.

[37] Humar A, Matas AJ.: Surgical complications after kidney transplantation. Semin Dial 18: 505-510, 2005. 